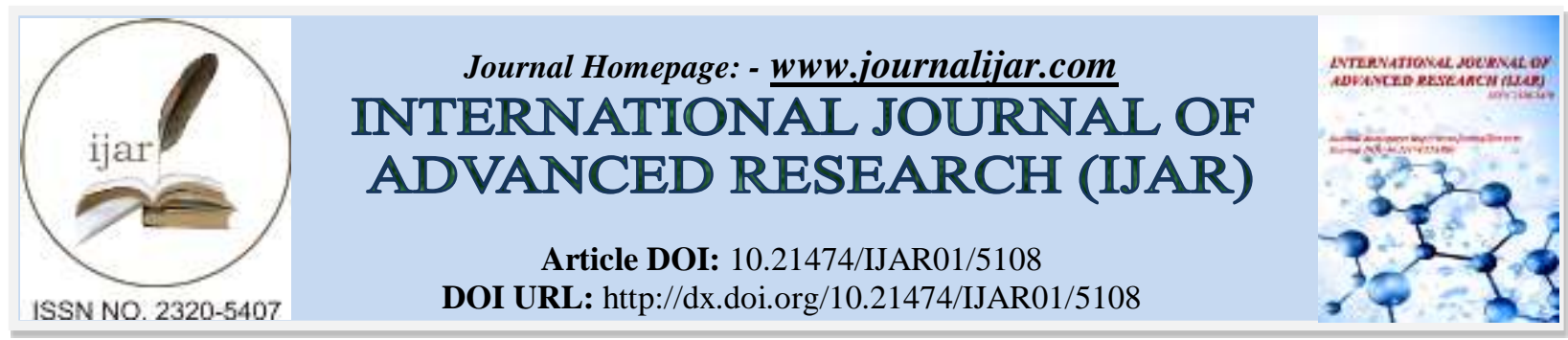

RESEARCH ARTICLE

\title{
GROWTH AND CHARACTERIZATION OF PURE AND CLOVE DOPED KDP CRYSTALS BY SLOW EVAPORATION METHOD.
}

\section{Usharani Pisipaty and P. Divya.}

Department of Chemistry, Sri Chandrasekharendra Saraswathi Viswa Mahavidyalaya University, Enathur, Kanchipuram - 631 561, Tamilnadu, India.

\section{Manuscript Info}

Manuscript History

Received: 08 June 2017

Final Accepted: 10 July 2017

Published: August 2017

Key words:-

Single crystal growth, non-linear optic,

Potassium dihydrogen phosphate (KDP),

clove, FTIR, XRD study, UV-Visible

spectroscopy, TG/DTA, SHG,

SEM,EDAX.

\begin{abstract}
Optically good quality pure and clove doped KDP crystals have been grown by slow evaporation method at constant temperature and their characterization has been studied. Slow evaporation method is very simple method and be utilized to synthesize crystals which are having low solubility if the optimum condition obtained properly. The presence of functional groups of crystals is qualitatively analyzed from FTIR spectra. X-ray diffraction study has been carried out in order to see the effect of dopants on the structural parameters of KDP. The powdered X-ray diffraction analysis revealed the tetragonal structure of KDP and doped crystals. Single crystal X-ray diffraction revealed the lattice parameter values. The grown clove doped KDP crystals were characterized by UV-Visble spectroscopy. The Stability and decomposition of pure and clove doped KDP Crystals are determined by TG/DTA Analysis. The second harmonic generation (SHG) was measured by using ND-YAG laser. The relative second harmonic generation (SHG) efficiency of clove doped KDP crystals was higher than the pure KDP crystals. SEM study was performed to indicate the influence of dopants on surface morphology of KDP crystals. EDAX study was used to know the idea about the elements present in the crystals.
\end{abstract}

Copy Right, IJAR, 2017,. All rights reserved.

\section{Introduction:-}

Nucleation process is the initial and most important phenomenon in liquid-solid phase transition[1]. Recently, nonlinear optics (NLO) is at the foremost of prevalent research due to its applications in frequency shifting, optical switching, optical memory and optical modulation for the technological areas such as telecommunications, optical interconnection and signal processing [2].

Clove is simple organic molecules with immense dipole moment and have the ability to from a large scale network of hydrogen bonds. Dopant is added to occupy the interstitial positions in the lattice and in turn this may lead to distinctive changes in the physical properties[3]. Inspite of having all good factors, the organic crystals could not be employed satisfactorily in devices because of their poor mechanical and thermal stability [4]. So, semi organic crystals having the properties of both inorganic and organic species, are expected to have good optical thermal and mechanical properties, Pooder[5] has reported that the addition of clove to KDP crystal enhances the second harmonic generation of KDP and also its mechanical strength. 
Potassium dihydrogen orthophosphate (KDP) $\mathrm{KH}_{2} \mathrm{PO}_{4}$ is an interesting material and, due to that fact, several research workers have shown considerable interest on it (Varma et al [6]; Henisch [7]; Rashkovich [8]; Udupa et al [9]; A research programme on the growth and physical properties of pure and impurtity added KDP crystals is being carried out in this laboratory.

Clove (Syzygiumaromaticum) is one of the most valuable spices that has been used for centuries as food preservative and for many medicinal purposes. Clove is native of Indonesia but nowadays is cultured in several parts of the world including Brazil in the state of Bahia. This plant represents one of the richest source of phenolic compounds such as eugenol, eugenol acetate and gallic acid and posses great potential for pharmaceutical, cosmetic, food and agricultural applications[10]. This review includes the main studies reporting the biological activities of clove and eugenol. The antioxidant and antimicrobial activity of clove is higher than many fruits, vegetables and other spices and should deserve special attention. A new application of clove as larvicidal agent is an interesting strategy to combat dengue which is a serious health problem in Brazil and other tropical countries[11]. Pharmacokinetics and toxicological studies were also mentioned. The different studies reviewed in this work confirm the traditional use of clove as food preservative and medicinal plant standing out the importance of this plant for different applications.

\section{Experimental Procedure and Characterization:-}

Potassium Dihydrogen Phosphate (KDP) is a well-known inorganic salt, which has been purified by repeated recrystallization using the method of dissolving in distilled water. Then the solution of KDP salts have been prepared by stirring well for three hours constantly using magnetic stirrer, till the salts have been fully dissolved in water. The prepared solution has been transfered into clean beaker and kept for crystallization at room temperature in a quiet place. Within four days the nucleation took place and a seed crystal in beaker has been obtained. To obtain clove extract doped crystal, clove extract was added to the saturated mother solution. Highly transparent and full faced crystals were obtained within three weeks. The pure KDP and clove doped KDP crystals grown are colorless and are shown in Figure 1 respectively. A slow evaporation method has been employed to grow clove extract doped KDP crystal .

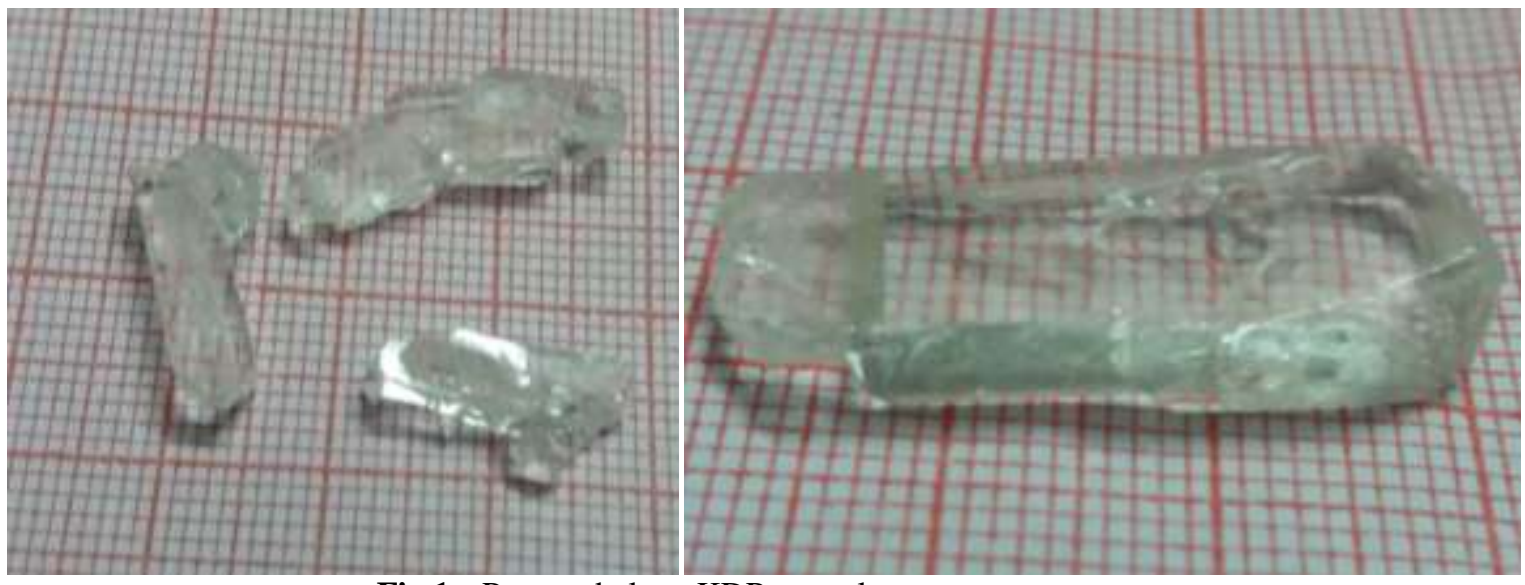

Fig.1:- Pure and clove KDP crystal

\section{Results and Discussion:- \\ FTIR spectral studies:-}

The Infrared spectral analysis is effectively used to understand the chemical bonding and it provides information about the functional groups present in the synthesized compound. The FTIR spectra have been recorded in the range 400 to $4000 \mathrm{~cm}-1$. The FTIR spectra of pure and clove extract doped KDP is shown in Figure $3.1 \& 3.2$ The observed frequencies and their assignments for pure and clove extract doped KDP crystals are listed in Table 1. 

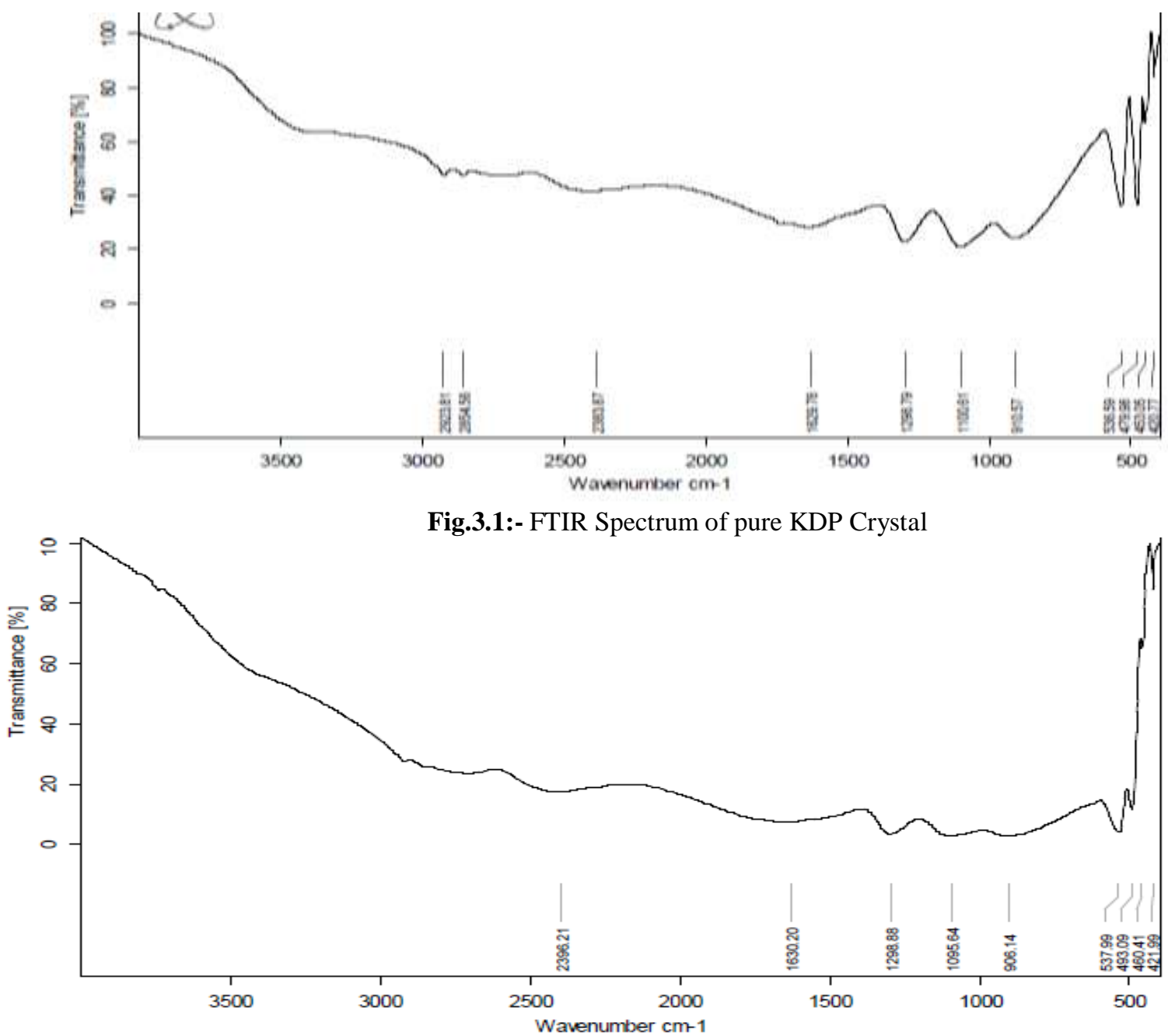

Fig.3.2:- FTIR Spectrum of clove doped KDP crystal.

Table.1:- The observed frequencies and their assignments for pure and ginger extract doped KDP crystals

\begin{tabular}{|l|l|l|}
\hline PURE KDP & KDP + CLOVE & ASSIGNMENT \\
\hline 2923 & ---- & O-H Stretching \\
\hline $\mathbf{2 8 5 4}$ & ---- & O-H Stretching \\
\hline $\mathbf{2 3 8 3}$ & $\mathbf{2 3 9 6}$ & $\begin{array}{l}\text { P-O-H Bonding of KDP } \\
\text { C=O stretching }\end{array}$ \\
\hline $\mathbf{1 6 2 9}$ & $\mathbf{1 6 3 0}$ & $\mathrm{NH}_{3}$ asym.bending \\
\hline $\mathbf{1 2 9 8}$ & $\mathbf{1 2 9 8}$ & P=O stretching \\
\hline $\mathbf{1 1 0 0}$ & $\mathbf{1 0 9 5}$ & P-O stretching \\
\hline $\mathbf{9 1 0}$ & $\mathbf{9 0 6}$ & N-H Wagging \\
\hline $\mathbf{5 3 6}$ & $\mathbf{5 3 7}$ & PO $_{4}^{3-}$ bending \\
\hline $\mathbf{4 5 3}$ & $\mathbf{4 6 0}$ & N-H Torsional oscillations \\
\hline
\end{tabular}

X-ray diffraction analysis:-

Powder X-ray diffraction analysis:-

Powder X-ray diffraction analysis was performed to confirm the quality of the crystals and to indentify the cell dimensions using Bruker A X3D8 PERT-PRO, advance model powder diffract meter with Cuk $\alpha$ radiations ( $\mathrm{I}=1.5405984)$. It is also used to confirm the physical phase of the crystal. X-ray diffraction study to identify the reflection planes. The XRD pattern of grown ginger extract doped KDP is shown in figure $3.3 \& 3.4$ 


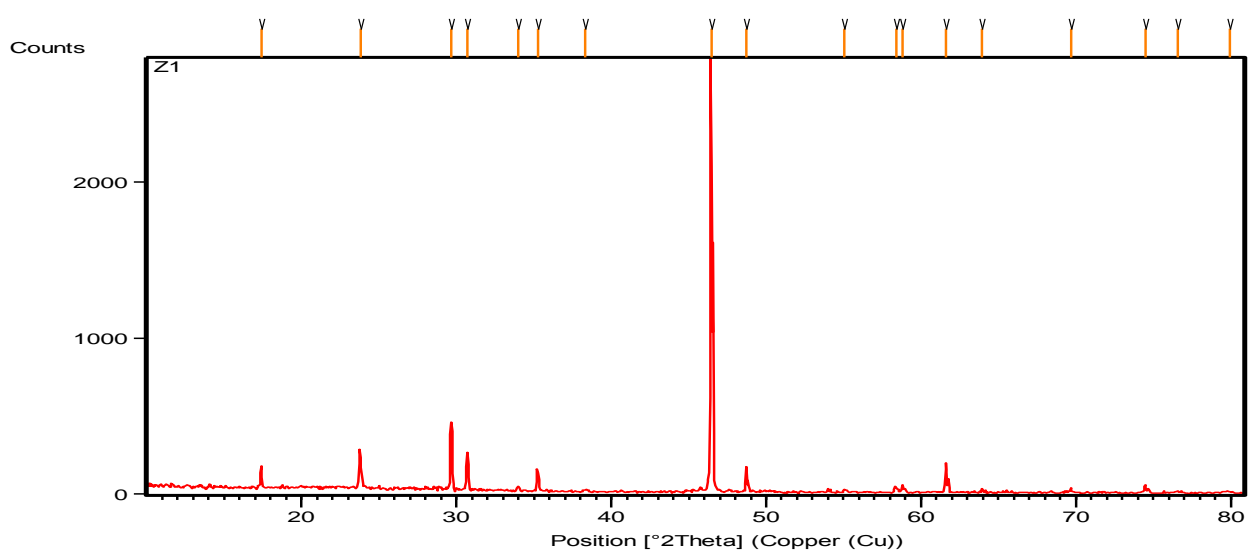

Fig. 3. 3:- Powder X-rd pattern of pure KDP Crystal

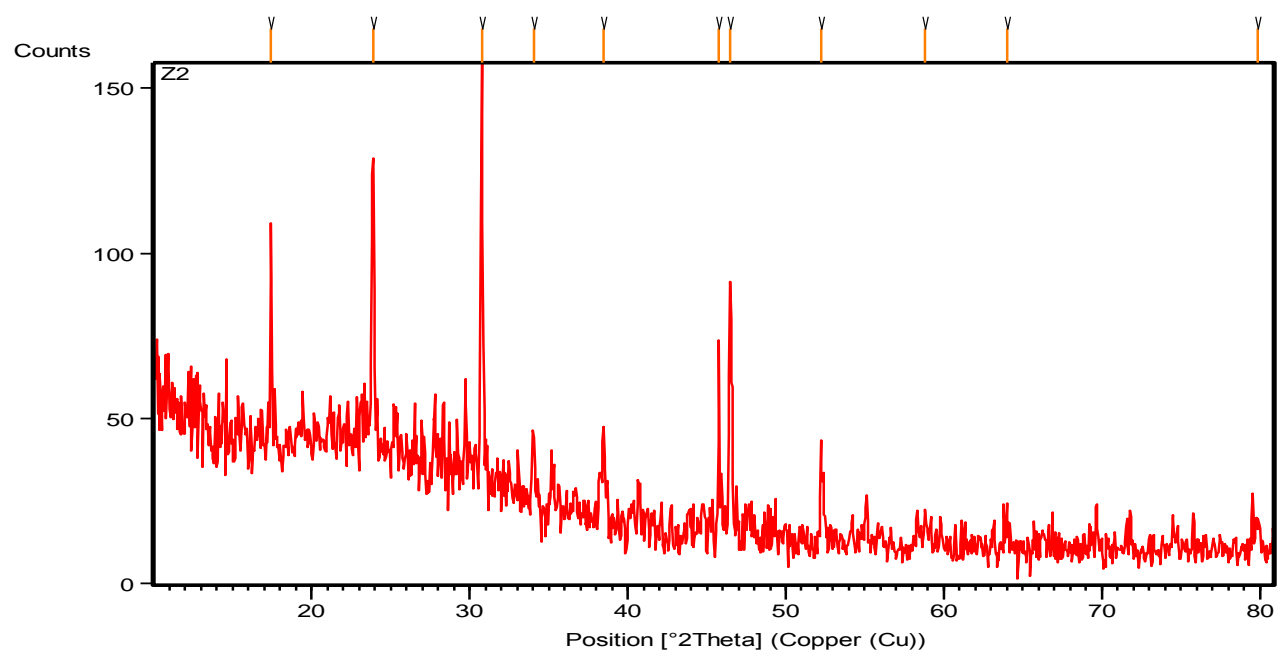

Fig.3.4:- Powder X-rd pattern of clove KDP Crystal

\section{Single crystal $x$-rd studies:-}

Single crystal X-ray diffraction data were recorded using MACH 3 Nonius CAD-4. X-ray diffractometer with $\mathrm{CuK} \alpha$ radiation. $(\mathrm{I}=1.540598 \AA$ ) for the grown crystals. It is confirmed from that study that pure and clove doped KDP crystals. The above results are in good agreement with earlier report

Table 2:- Lattice Parameter Values For Pure And Clove Doped Kdp Crystals

\begin{tabular}{|c|c|c|c|c|c|c|}
\hline S.NO & Sample & $\begin{array}{l}\text { Lattic } \\
\mathbf{a}=\mathbf{b}(\AA\end{array}$ & & $\alpha=\beta=\gamma$ & $\begin{array}{l}\text { Cell volumes } \\
\mathrm{V}(\AA)\end{array}$ & Structure \\
\hline 1 & Pure KDP & 7.449 & 6.968 & 90 & 386 & Tetragonal \\
\hline 2 & $\begin{array}{l}\text { KDP+CLOVE } \\
1 \mathrm{ML}\end{array}$ & 7.468 & 6.999 & 90 & 390 & Tetragonal \\
\hline
\end{tabular}

\section{UV - Visible spectroscopy:-}

The optical properties of material are important as they provide information on the electronic band structure, localised state and types of optical transitions. The UV visible transmission spectrum was recorded using perkin Elmer Model-Lambda 35 spectrometer in the range 190-1100 mm. From the spectrum it is observed that the pure and clove doped KDP crystals showed little absorbance in the entire visible region. The addition of pure and clove seems to have increased the crystalline perfection in KDP there by resulting, lesser absorption. The cut off wevelength is around $(\sim 276 \mathrm{~nm})$ for pure and clove doped KDP crystals. The UV Visible data reveals that clove dopants improved the optical transparancy of the crystal and confirm the betterment of optical quality. The transmittance comparatively increased when clove are doped to KDP crystals fig (3.5 \& 3.6) 


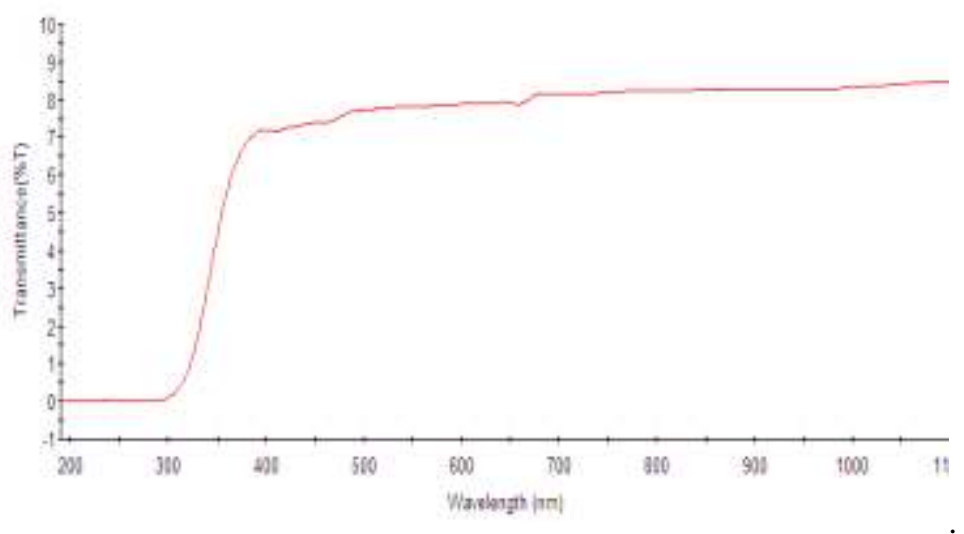

Fig.3.5:- Reflectance spectra of ginger extract doped KDP crystal.

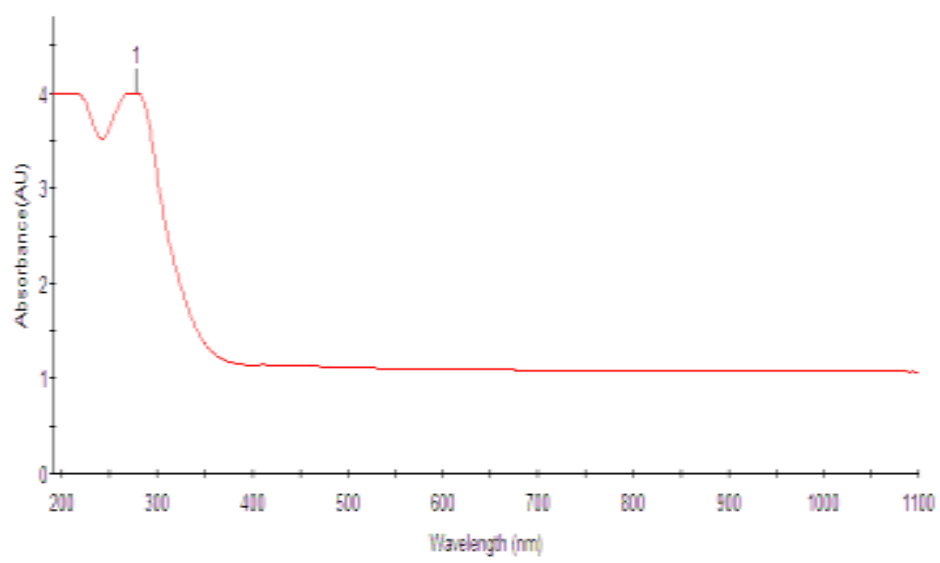

Fig.3.6:-Absorbance spectra of ginger extract doped KDP crystal.

Thermal Studies:-

Thermal studies gives an idea about the stability and decompostion of crystals TGA and DTA curve for pure and clove KDP crystals have been recorded on Perkin Elmer Dimmer TGDTA at a heating rate $15^{\circ} \mathrm{c} / \mathrm{mm}$ under argon atmosphere. For pure KDP crystal after temperature about $230^{\circ} \mathrm{C}$ the weight loss starts due to the liberation of volatile substances, probably water molecule of decomposed KDP. The weight loss starts at $263^{\circ} \mathrm{C}$ and continues upto $350^{\circ} \mathrm{C}$, which is possibly due to decomposition of the KDP.

TGA for pure KDP shows endothermic transition around $263^{\circ} \mathrm{C}$ followed by another endothermic peak at $295^{\circ} \mathrm{C}$ i.e., midpoint $285.43^{0} \mathrm{C}$. TGA shows almost complete weight loss and the residual weight obtained was found to be $13.7 \%$. The total mass loss and saturation occurs at $348.7^{\circ} \mathrm{C}$. They might be attributed to high temperaturs phase transition of KDP. In addition a significant splitting appears in the DTA peak at $285.43^{\circ} \mathrm{C}$. This is possibly indicates the decormposition of $\mathrm{KDP}$ in to $\mathrm{KPO}_{3}$ and water.

$2 \mathrm{KH}_{2} \mathrm{PO}_{4} \rightarrow 2 \mathrm{KPO}_{3}+2 \mathrm{H}_{2} \mathrm{O}$

The satellite peak might correspond to the low temperature structural phase transition of KDP. In $285.43^{\circ} \mathrm{C}$ temperature the liberation of volatile substance such as carbon dioxide and ammonia occurs compare to pure KDP $(0.750 \mathrm{mg})$ Weight loss more in clove $(0.828 \mathrm{mg})$ because of inclusion of clove into the KDP formation and makes crystal soft and free from stress. 


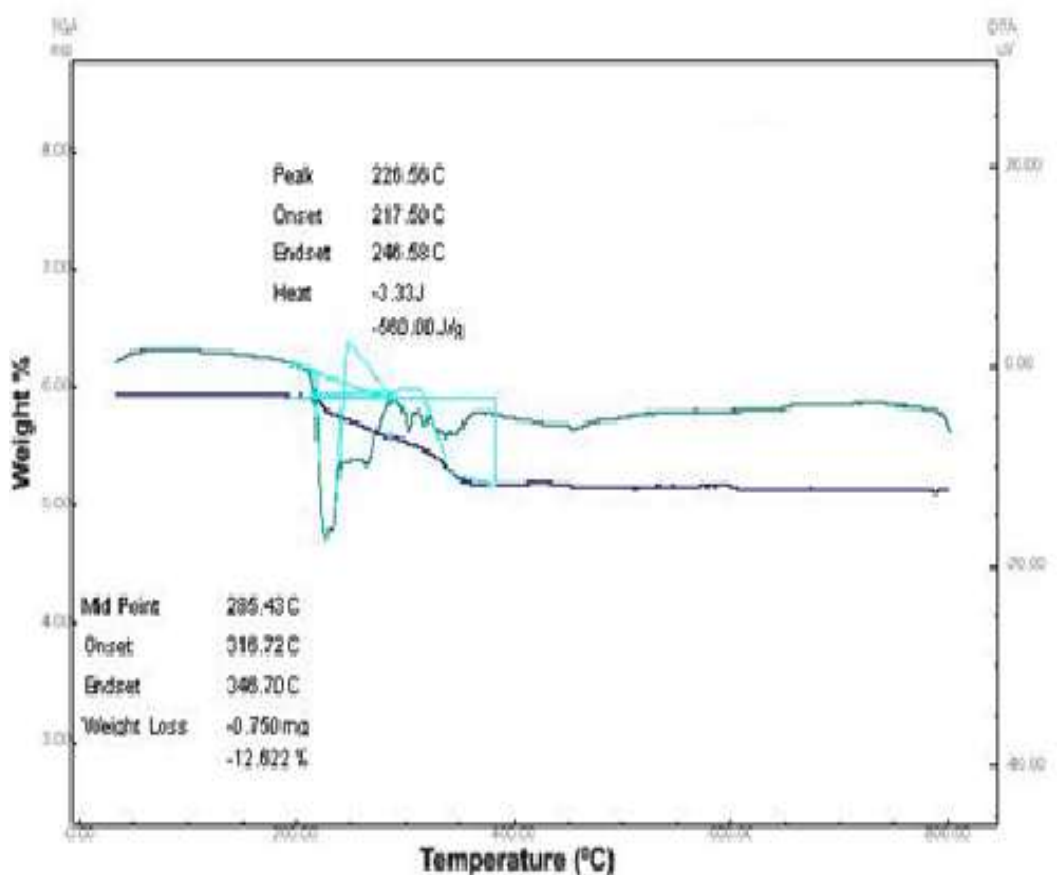

Fig.3.7:- TG/DTA curve of pure KDP Crystal

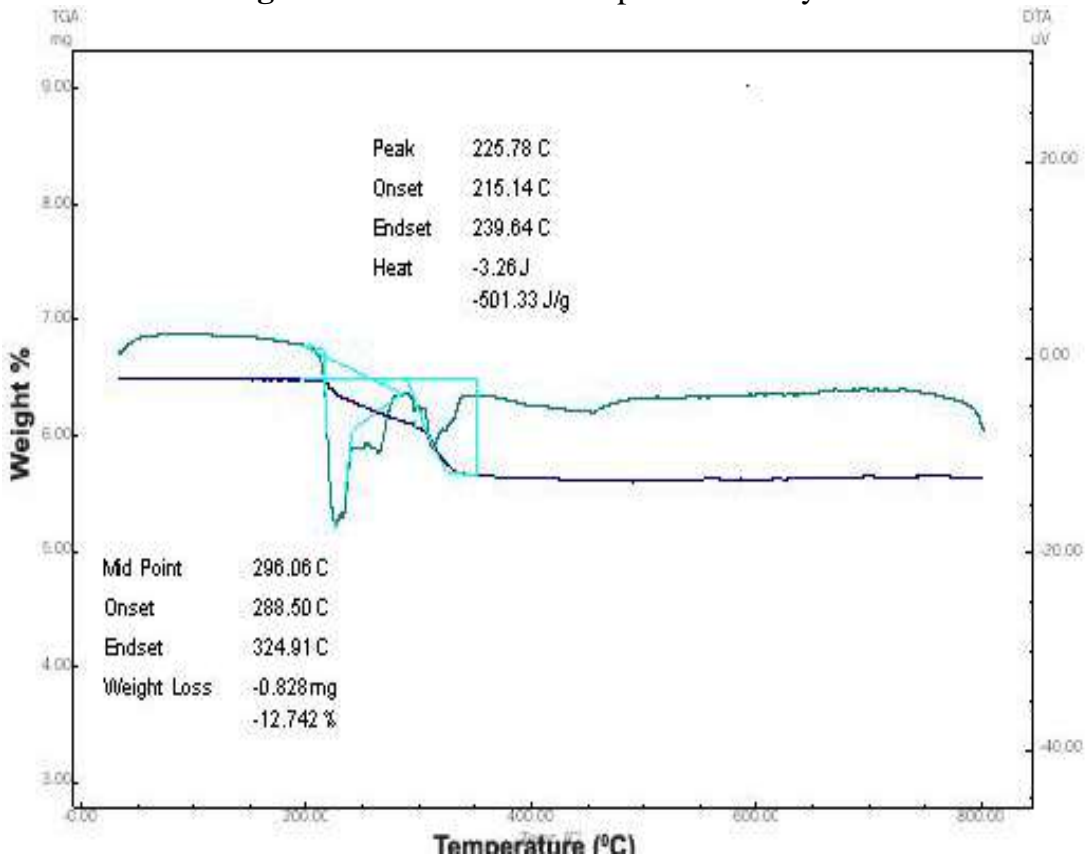

Fig.3.8:- TG/DTA curve of clove doped KDP Crystal

\section{NLO TEST:-}

The most widely used technique for confirming the SHG efficiency of NLO materials, to identify the materials with noncentrosymmetric crystal structures, is the Kurtz powder technique. In this method, the powdered sample with an average particle sizes in the range $125-150 \mu \mathrm{m}$ is filled in micro-capillary tube about $1.5 \mathrm{~mm}$ diameter, Q-switched Nd: YAG laser emitting a fundamental wavelength of $1064 \mathrm{~nm}$ with pulse width $8 \mathrm{~ns}$ was used. The SHG was confirmed by the emission of green radiation $(532 \mathrm{~nm})$. The input laser energy incident on the sample was $4.5 \mathrm{mj} / \mathrm{pulse}$ an energy level optimized not to cause any chemical decomposition of the sample. The SHG efficiency of pure KDP and clove doped KDP are shown in Table. 


\begin{tabular}{|l|l|l|l|}
\hline Sl. No. & Name of the Sample & $\begin{array}{l}\text { Output Energy } \\
\text { (milli joule) }\end{array}$ & $\begin{array}{l}\text { Input Energy } \\
\text { (joule) }\end{array}$ \\
\hline 1 & PURE KDP & 11.38 & 0.701 \\
\hline 2 & KDP + CLOVE & 15.34 & 0.701 \\
\hline $\mathbf{3}$ & KDP (Reference) & $\mathbf{8 . 9 1}$ & $\mathbf{0 . 7 0 1}$ \\
\hline
\end{tabular}

Scanning electron microscope (SEM) studies:-

It can be confirmed by SEM images of KDP, that the growth conditions are unconstrained and the crystallites obtained are on the whole as seen in fig 3.9. Due to the different atom interaction among additives clove doped KDP crystals. The effect of clove on the crystal surface morphology influences the volume of crystallites consequently the dopant clove affects the expanded capacity of crystallographic plane resulting in various crystallites figure $3.9 \&$ 3.10 .

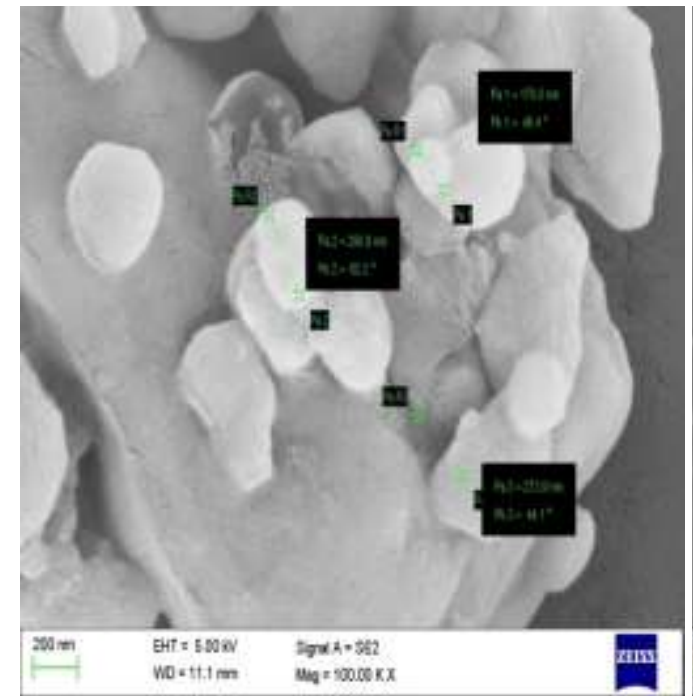

Fig.3.9:- Sem pattern of pure KDP Crystal

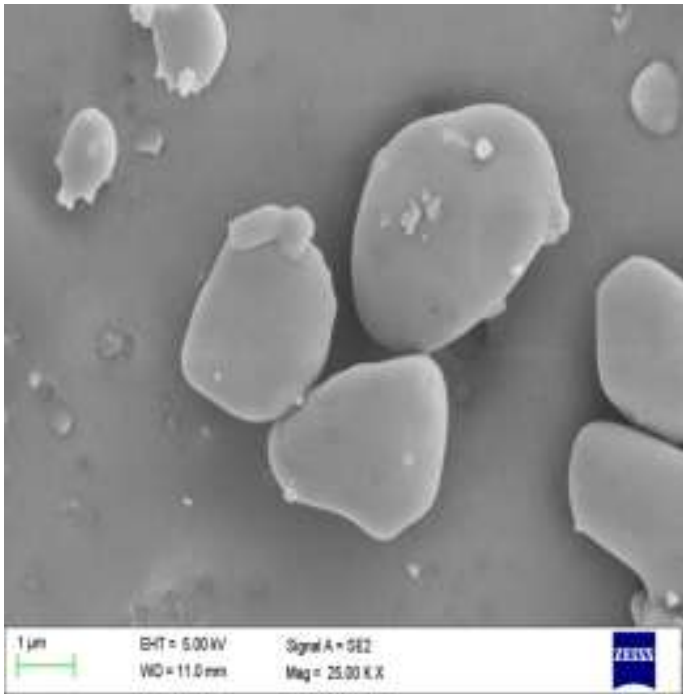

Fig.3.10: Sem pattern of clove doped KDP

energy dispersive $x$-ray analysis (edax):-

Energy dispersive X-ray analysis (EDAX) used in conjunction with all types of electron microscopes has become an important tool for characterizing the elements present in the crystals. In the present study, the grown crystals were analyzed by an FEI QUANTA 200F energy dispersive X-ray analyzer. The results obtained in EDAX of the pure and doped KDP crystal are shown in Fig.3.11. This confirms the presence of clove in the doped KDP samples. From the EDAX spectra the presence of clove doped KDP crystal in identified.

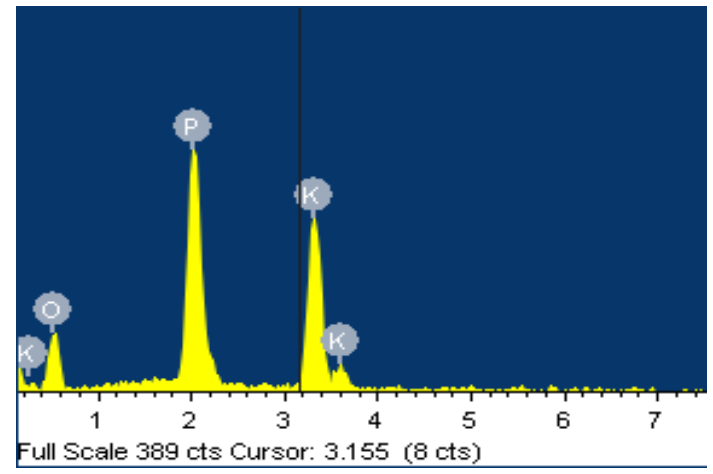

Fig 3.11:- EDAX Spectrum of pure KDP

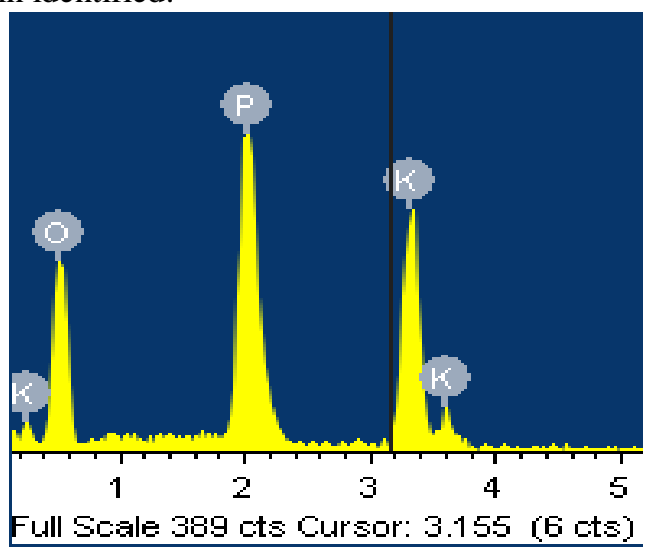

Fig 3.12:- EDAX Spectrum of clove doped 


\section{Conclusion:-}

Optically good quality crystals of pure KDP and clove extract doped KDP crystals have been grown by slow evaporation method. UV-Vis spectra showed that the grown crystal was optically transparent through 200-800 nm and hence suggests the suitability of this material for optical devices. Powder X-ray diffraction analysis confirms the crystalline nature of grown crystal. The FTIR spectral analysis confirms the presence of functional groups in the crystals. The SHG test proves that the grown crystals are potential candidates for nonlinear applications. The high optical transparency and SHG properties prove the optical quality and suitability of the grown KDP crystal doped with clove extract for optoelectronic device applications

\section{References:-}

1. J.M. Kavitha, K. Senthalakshmi, C. Mahadevan and Y. Permila.Rachelin, Bull. Mater, Sci. Vol.22, No. 4, June 1999 pp. 821-826

2. A. Kandasamy, R. Siddeswaran, P. Murugakoothan, P. Suresh Kumar, R. Mohan, Cryst. Growth Des. 7 (2007 183-186)

3. C.K. Mahadevan, phy.N.403(208) $3164-3167$.

4. S. Gunasekaran and G.R. Ramkumar, Indian J. Phys. 83(11), 1549-1555 (2009)

5. J. Podder J. Cryst. Growth 23770 (2002)

6. Varma K.B.R. Ramanaish K.V. and Rao K.V. 1983 Bull. Mater, Sci. 539

7. Henisch H.K. 1988 Crystals in gels and Liesegangrigns (Cam bridge: Cambridge University Press)

8. Rashkovich L.N. 1991 KDP family single Crystals (New York: Adam Hilger)

9. Udupa K.S. Mohan, Rao, P. SriramanaAirthal, Bhat A.P. and Avasthi D.K. 1997 Bull.Mater., Sci.20 1069

10. "Clove". MedlinePlus, U.S. National Library of Medicine and National Institutes of Health. 2014. Retrieved August 18, 2014.

11. "Clove (Eugenia aromatica) and Clove oil (Eugenol)". National Institutes of Health, Medicine Plus. nlm.nih.gov. February 15, 2012. Retrieved September 7, 2012. 